\title{
Exposure to Uteroplacental Insufficiency Reduces the Expression of Signal Transducer and Activator of Transcription 3 and Proopiomelanocortin in the Hypothalamus of Newborn Rats
}

\author{
ANTONELLA PUGLIANIELLO, DANIELA GERMANI, AND STEFANO CIANFARANI \\ Department of Public Health and Cell Biology, 'Rina Balducci' Center of Pediatric Endocrinology, Tor Vergata University, 00133 \\ Rome, Italy
}

\begin{abstract}
IUGR has been linked to the development of type 2 diabetes. Recent data suggest that some of the molecular defects underlying type 2 diabetes reside in the CNS. Disruption of the signal transducer and activator of transcription 3 (STAT3) in the hypothalamic neurons expressing leptin receptor, results in severe obesity, hyperglycaemia, and hyperinsulinemia. Our aim was to investigate the expression of STAT3 and its downstream effector proopiomelanocortin (POMC) in IUGR rats obtained by uterine artery ligation. On day 19 of gestation, time-dated Sprague-Dawley pregnant rats were anesthetized, and both the uterine arteries were ligated. At birth, hypothalamus was dissected and processed to evaluate the expression of STAT3, its phosphorylated form, and POMC. STAT3 mRNA, STAT3 protein, phosphorylated STAT3, POMC mRNA, and POMC protein were significantly reduced in IUGR versus sham animals $(p<0.0001, p<0.05$ and $p<0.001, p<0.01, p<0.01$, respectively). No significant differences either in serum leptin concentrations or in hypothalamic leptin receptor expression were observed. Our results suggest that an abnormal intrauterine milieu can affect the hypothalamic expression of STAT3 and POMC at birth, altering the hypothalamic signaling pathways that regulate the energy homeostasis. (Pediatr Res 66: 208-211, 2009)
\end{abstract}

$I^{\prime}$ UGR is associated to a higher risk of developing insulin resistance, type 2 diabetes mellitus and cardiovascular disease in adulthood (1-6). These observations have led to the hypothesis that adult metabolic and cardiovascular disease may arise in utero as a result of programming of key endocrine and metabolic pathways during suboptimal intrauterine conditions associated with impaired fetal growth. This hypothesis has been tested experimentally in a number of species, using a range of techniques to impair fetal growth (7). However, the mechanisms underlying the association between an abnormal uterine milieu and the development of metabolic alterations in adulthood are not known. Ligation of the uterine arteries in rats has been used as an animal model of uteroplacental insufficiency, which limits the supply of substrates and hormones to the fetus $(4,5)$. This abnormal intrauterine environment affects the development of the fetus, ultimately lead-

Received January 5, 2009; accepted March 10, 2009.

Correspondence: Stefano Cianfarani, M.D., Department of Public Health and Cell Biology, 'Rina Balducci' Center of Pediatric Endocrinology, Room E-178, Tor Vergata University, Via Montpellier 1, 00133 Rome, Italy; e-mail: stefano.cianfarani@ uniroma2.it

No financial assistance was received to support this study. ing to a growth-retarded fetuses, and the development of diabetes in adulthood independently of postnatal diet $(8,9)$.

The CNS, and in particular the hypothalamus, is a major regulator of glucose homeostasis (10). The hypothalamus integrates nutritional, endocrine, and neural cues signaling the body's metabolic and nutritional status. Neurons in the hypothalamus are primary targets of a number of key metabolic signals. Hypothalamic neurons, in turn, target several downstream sites to influence the coordinated autonomic, behavioral, and endocrine responses. These signals should normally activate a negative feedback loop between the availability of nutrients and their intake and metabolism (11-13). It has recently been proposed that some of the molecular defects underlying type 2 diabetes may reside in the CNS, supporting the concept that type 2 diabetes is, at least in part, a hypothalamic disorder (12-14).

The family of signal transducers and activators of transcription (STAT) proteins comprises a class of transcription factors activated in response to a large number of cytokines, growth factors, and hormones. Upon activation after the binding of ligands to their receptors, STAT proteins dimerize, translocate to the nucleus, and bind to the promoters of specific target genes (15). To date, seven mammalian members of the STAT family have been identified (15). STAT3-deficient mice die during early embryogenesis, but the role of STAT3 in adult tissues can be assessed by using the cre-loxP recombination system to ablate the gene later in life. Analyses of tissuespecific STAT3-deficient mice indicate that STAT3 plays a crucial role in a variety of biologic functions including energy balance, reproduction, and intermediate metabolism. Mice with a neuron-specific disruption of STAT3 throughout the CNS are hyperphagic, obese, diabetic, and infertile (16). Furthermore, the deletion of STAT3 via the rat insulin promoter leads to a tissue-specific knockout of STAT3 in a subset of hypothalamic cells, leading to impaired glucose tolerance and obesity (17-19).

STAT3 has been long implicated in the regulation of energy homeostasis through the fat-derived cytokine leptin. Although leptin can activate several STAT proteins, including STAT3, 5, and 6 , in vitro (20), only STAT3 is activated in the hypothalamus

\footnotetext{
Abbreviations: POMC, proopiomelanocortin; STAT3, signal transducer and
} activator of transcription 3 
in vivo on leptin administration $(21,22)$. Activation of STAT3 in response to leptin within the hypothalamus can be detected in both the networks that mediate anorexogenic [proopiomelanocortin (POMC) and cocaine and amphetamine regulated transcript(CART)] and orexogenic neuropeptide Y (NPY) and agouti-related protein physiology (23).

In this study, we examined whether the exposure to uteroplacental insufficiency obtained by bilateral uterine artery ligation associates to a change in the hypothalamic expression of STAT3 and POMC in IUGR rats at birth.

\section{MATERIALS AND METHODS}

Animal model. Time-dated Sprague-Dawley pregnant rats (Harlan Sprague Dawley Inc.) were individually housed under standard conditions and were allowed free access to standard chow and water. On day 19 of gestation (term is $22 \mathrm{~d}$ ), the maternal rats were anesthetized with intramuscular injections of xylazine $(8 \mathrm{mg} / \mathrm{kg}$ ) and ketamine $(40 \mathrm{mg} / \mathrm{kg}$ ) (Sigma-Aldrich, St. Louis, MO), and the abdomen was opened along the midline. Suture was placed around both the uterine arteries and then either tied or withdrawn before closing the abdomen $(24,25)$. Dams recovered quickly from uterine artery ligation and sham procedures, and resumed feeding the same day. After recovery, rats had ad libitum access to food and water. The pregnant rats were allowed to deliver spontaneously, and approximately $8 \mathrm{~h}$ after delivery, pups were weighed and killed by cervical dislocation. Tissue was immediately harvested, frozen in liquid nitrogen, and stored at $-80^{\circ} \mathrm{C}$. Ten sham and 10 IUGR rats from four different litters per each study group were randomly selected according to computer-generated random numbers and tested. Surgical excision of hypothalamus was performed by microcurette. All procedures complied with Italian regulations for laboratory animal care, according to the guidelines and under supervision of the Animal Technology Station, Interdepartmental Service Center, Tor Vergata University, Rome, Italy.

Plasma assays. At birth, 10 sham and 10 IUGR pups were decapitated, blood was collected and centrifuged at $1900 \times \mathrm{g}$ at $4^{\circ} \mathrm{C}$ for $10 \mathrm{~min}$, and the plasma was stored at $-80^{\circ} \mathrm{C}$. Glucose was determined using a colorimetric commercial kit (Sigma Chemical Co.). Plasma insulin concentrations were measured in duplicate by a rat or mouse insulin ELISA kit, using rat insulin as the standard (Linco Research, St. Charles, MO) according to the manufacturer's instructions. The intraassay CV was $1.2-8.4 \%$, the interassay CV was $6.0-17.9 \%$, and the sensitivity limit was $0.2 \mathrm{ng} / \mathrm{mL}$. Leptin concentrations were measured using a leptin ELISA kit (R\&D Systems, UK) according to the manufacturer's instructions. The intraassay CV was $3.8-4.3 \%$, the interassay CV was $5-7.6 \%$, and the sensitivity limit was $22 \mathrm{pg} / \mathrm{mL}$.

RNA isolation and cDNA synthesis. Total RNA was extracted using TriPure (Roche Applied Science) according to the manufacturer's instructions and quantified in duplicate using UV absorbance at $260 \mathrm{~nm}$. Gel electrophoresis confirmed the integrity of the samples. One microgram of RNA, pretreated with RNase free DNase (Invitrogen Co.), was transcribed into the cDNA using the High-Capacity cDNA Archive Kit (Applied Biosystems) in a final volume of $50 \mu \mathrm{L}$ following the manufacturer's protocol. To minimize variation in the reverse transcription reaction, all RNA samples from a single experimental setup were reverse transcribed simultaneously.

Real-time RT-PCR. Real-time RT-PCR was performed on an ABI PRISM 7300 Sequencer Detector (Applied Biosystems). PCR primers and TaqMan probes to amplify and detect STAT3, POMC, leptin receptor, and the housekeeping gene $18 \mathrm{~S}$ were commercially available as inventoried assay (Assayon-demand Gene Expression Product; Applied Biosystems). 18S was used as an internal control for differences in cDNA loading. Before the use of $18 \mathrm{~S}$ as a control, parallel and serial dilutions of cDNA were quantified to prove the validity of using $18 \mathrm{~S}$ as an internal control. The real-time RT-PCR amplification was performed in hypothalamic tissue from 10 sham and 10 IUGR rats. Experiments were performed in triplicate using 96-well tray and optical adhesive covers (Applied Biosystems) in a final reaction mixture of $20 \mu \mathrm{L}$ containing $4 \mu \mathrm{L}$ of undiluted cDNA. Real-time PCR was performed using Platinum Quantitative PCR SuperMix-UDG with ROX (Invitrogen Co.). The cycling consisted of $2 \mathrm{~min}$ at $50^{\circ} \mathrm{C}, 2 \mathrm{~min}$ at $95^{\circ} \mathrm{C}$ followed by 40 cycles of $95^{\circ} \mathrm{C}$ for $15 \mathrm{~s}$ and $60^{\circ} \mathrm{C}$ for $45 \mathrm{~s}$. Determination of reaction efficiency was routinely used as an internal quality control for adequate assay performance. Crossing of threshold values obtained for the target gene were normalized against each individual $18 \mathrm{~S}$ value, which was run in the same well of the real time RT-PCR run. Relative quantification of PCR products was performed using Relative Quantification Study Software (Applied Biosystems). Results are expressed in raw relative quantification \pm standard errors.
Western immunoblotting. Tissue was homogenized in ice with lysis buffer (50 mM HEPES pH 7.4, $150 \mathrm{mM} \mathrm{NaCl}, 10 \mathrm{mM} \mathrm{NaF}, 1 \mathrm{mM} \mathrm{Na}_{3} \mathrm{VO}_{4}, 10 \%$ glycerol, $0.5 \%$ Triton $\mathrm{X}-100,5 \mathrm{mM}$ EDTA, $10 \mu \mathrm{L} / \mathrm{mL}$ cocktail protease inhibitors). Lysates were clarified by centrifugation at $13,000 \times \mathrm{g}(30 \mathrm{~min}$, $4{ }^{\circ} \mathrm{C}$ ), and protein concentrations in the supernatant were determined by the Bradford assay (Bio-Rad Laboratories, CA) using BSA as a standard. Eighty micrograms of the extracted proteins were separated by NuPAGE Novex 4-12\% Bis-Tris precast gel (Invitrogen) and blotted onto ECL nitrocellulose membrane (Amersham Biosciences UK Ltd., Little Chalfont, Buckinghamshire, UK). The filter was blocked with $5 \%$ nonfat dry milk in PBS- $0.1 \%$ Tween 20 and then incubated with STAT3 and phospho-STAT3 rabbit polyclonal antibody (Cell Signaling Technology Inc., Danvers, MA) and POMC goat polyclonal antibody (Novus Biologicals). After several washes in PBS-0.1\% Tween 20, horseradish peroxidase-conjugated secondary antibody was added for $1 \mathrm{~h}$ at room temperature. The labeled bands were detected using Pierce western blotting system, according to manufacturer's specifications. After protein detection, membranes were stripped with Restore Western Blot Stripping Buffer (Pierce, Rockford, IL) and reblotted with rabbit HRP-conjugated actin antibody (1:1000; Santa Cruz). Densitometry analysis of bands was performed using Image Quant 5 software (Molecular Dynamics).

Statistical analysis. Statistical analysis was performed using Sigma Chemical Co. Plot for Windows Version 13.0 (SPSS Inc, Chicago, IL). Differences in gene expression between sham and IUGR rats were analyzed with one-way ANOVA. Differences between means from plasma assays and densitometric analyses were assessed by unpaired two-tailed t test. Differences were considered statistically significant at $p<0.05$.

\section{RESULTS}

Animal weights and metabolic profile. Thirty percent of IUGR animals died or underwent partial resorption, particularly those located at the vaginal end of the uterine horn. Birth weights of IUGR animals were significantly lower than those of controls (mean weight $\pm \mathrm{SD}, 4.0 \pm 0.57$ versus $6.5 \pm$ $0.32 \mathrm{~g} ; p<0.001)$. No significant differences were observed in blood glucose, insulin, and leptin levels.

Expression of STAT3 in the hypothalamus. The expression of STAT3 in the hypothalamus of sham $(n=10)$ and IUGR rats $(n=10)$ from different litters was analyzed by quantitative RT-PCR at day 0. The expression of STAT3 resulted significantly lower (by approximately $37 \%$ ) in IUGR pups $(p<0.0001$, Fig. 1$)$.

Immunoblot analysis showed a significant reduction of both the total STAT3 protein (by approximately 73\%, $p<0.05$, Fig. 2) and phosphorylated STAT3 (by approximately $52 \%$ less, $p<0.001$, Fig. 2) in IUGR pups.

Expression of POMC in the hypothalamus. Because one of the STAT3 downstream genes is POMC, a major regulator of satiety and energy balance, its mRNA and protein expression was affected. The expression of POMC was measured by quantitative RT-PCR in the hypothalamus of sham $(n=10)$ and IUGR rats ( $n=10$ from different litters) at day 0 . The expression of POMC resulted significantly lower $(60 \%$ less) in IUGR pups ( $p<0.01$, Fig. 3). Immunoblot analysis showed a significant reduction of POMC protein by $63 \%$ $(p<0.01$, Fig. 4).

Expression of leptin receptor in the hypothalamus. Leptin is a major regulator of STAT3 and POMC expression in the hypothalamus. As serum leptin concentrations were not significantly different between IUGR and sham animals, we examined whether a different expression of hypothalamic leptin receptors could account for the differences observed in STAT3 and POMC gene expression. The expression of leptin receptor was measured by quantitative RT-PCR. No signifi- 


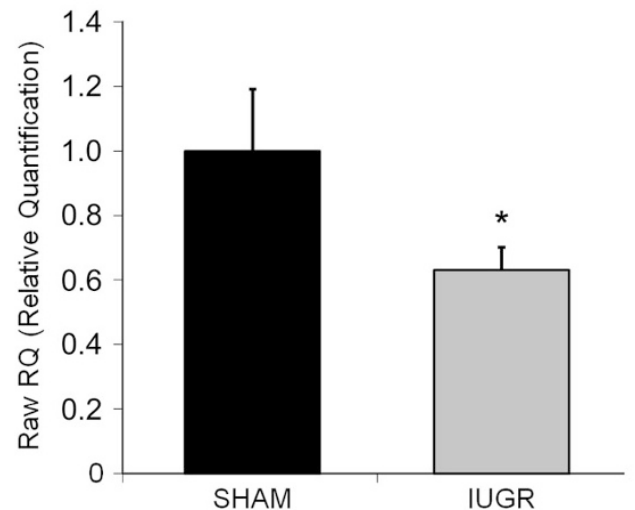

Figure 1. STAT3 mRNA expression in the hypothalamus of sham $(n=10)$ and IUGR rats $(n=10)$. Transcripts were measured by real-time RT-PCR using appropriate primers and normalized to $18 \mathrm{~S}$ mRNA. Data are expressed as relative quantification $v s$ SHAM group $(R Q=1)$. Bars represent standard errors, $* p<0.0001$.

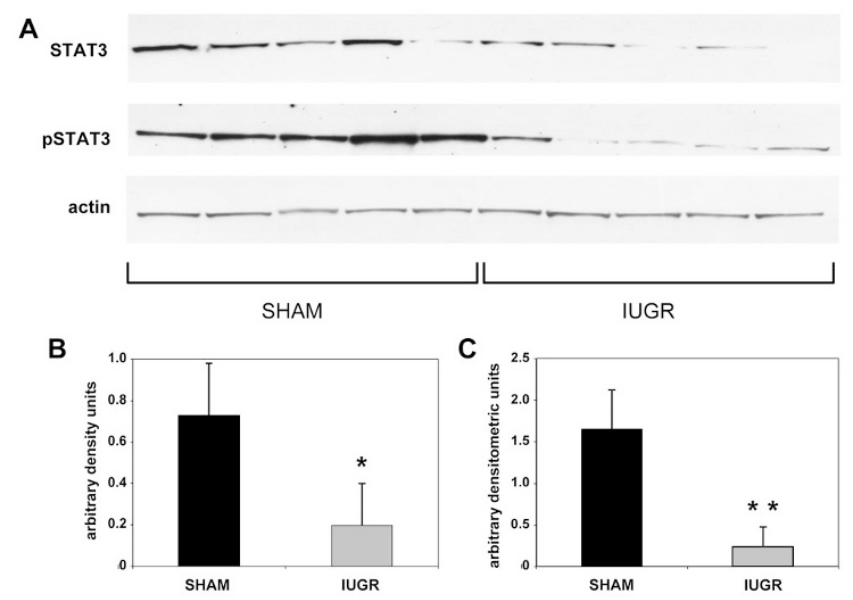

Figure 2. STAT3 and pSTAT3 protein expression in the hypothalamus of sham $(n=10)$ and IUGR rats $(n=10)$ on day $0 . A$, western immunoblotting analysis; $B$, densitometric analysis. $C$, densitometric analysis of phospherylated STAT 3. *p $<0.05, * * p<0.001$.

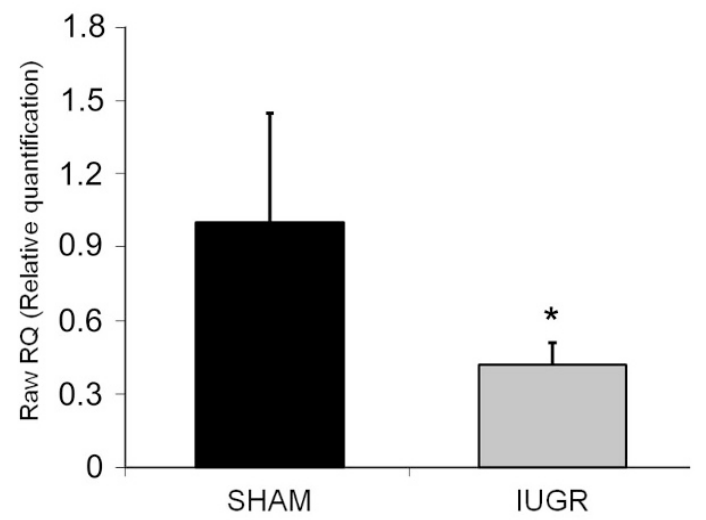

Figure 3. POMC mRNA expression in the hypothalamus of sham $(n=10)$ and IUGR rats $(n=10)$. Transcripts were measured by real-time RT-PCR using appropriate primers and normalized to $18 \mathrm{~S}$ mRNA. Data are expressed as relative quantification $v s$ sham group $(R Q=1)$. Bars represent standard errors, $* p<0.01$.

cant difference in the hypothalamic leptin receptor expression was found at day 0 between sham $(n=10)$ and IUGR rats $(n=10)$.

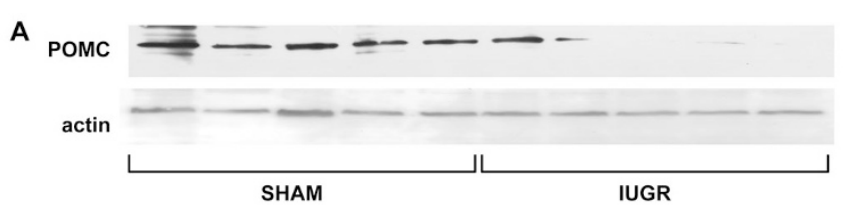

B

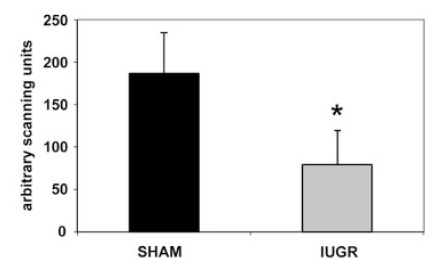

Figure 4. POMC protein expression in the hypothalamus of sham $(n=10)$ and IUGR rats $(n=10)$ on day 0 . A, western immunoblotting analysis; $B$, densitometric analysis, ${ }^{*} p<0.01$.

\section{DISCUSSION}

STAT3 is broadly expressed in the CNS during development and adulthood, and it seems to play a key role in the hypothalamic signaling that regulates the energy expenditure. The fact that neural-specific disruption of STAT3 exhibits all four characteristic defects (obesity, decreased linear growth, infertility, and high corticosterone) of leptin receptor $(\mathrm{db} / \mathrm{db})$ and ligand $(\mathrm{ob} / \mathrm{ob})$ mutants provides convincing evidence that STAT3 mediates most hypothalamic leptin function (16).

In attempt to investigate the mechanisms underlying the association between IUGR and postnatal metabolic risk, we used an animal model of IUGR induced by bilateral uterine artery ligation (9). In this model, blood flow to the fetus is not ablated but is reduced to a degree that mimics human pregnancies complicated by uteroplacental insufficiency (9). The resulting uteroplacental insufficiency leads to the growthretarded fetuses with a metabolic profile very similar to that of IUGR human fetuses $(8,9,24)$. These animals exhibit mild peripheral insulin resistance and $\beta$-cell secretory defects very early in life but have adequate compensatory insulin secretion for several weeks. However, $\beta$-cell compensation fails eventually, and overt diabetes occurs.

This study shows for the first time a down-regulation of the expression hypothalamic STAT3 in animals exposed to uteroplacental insufficiency during pregnancy. The reduction of phosphorylated STAT3 is likely a consequence of the lower content of the upstream nonphosphorylated counterpart.

This finding is consistent with a compensatory mechanism induced by fetal exposure to malnutrition. In response to reduced substrate transfer from the mother, the fetus undergoes adaptive changes finalized to replenish energy stores (26). This adaptation may reflect the developmental plasticity, which enables the organism to change structure and function in response to environmental cues (27).

The observed down-regulation of STAT3 expression in the hypothalamus of IUGR rats could thus represent a homeostatic adaptive response. However, in case this central feedback becomes permanent, the animals will develop hyperphagia, obesity, and diabetes (16). It has to be pointed out, however, that our study was limited at birth. Therefore, the present data do not permit us to know whether the changes in 
gene expression observed at birth are transient or permanent, eventually leading to obesity, insulin resistance, and type 2 diabetes in adulthood, as previously described in the same animal model (9).

POMC, a downstream effector of STAT3, represents the polypeptide precursor from which melanocortins, such as $\alpha$-melanocyte stimulating hormone ( $\alpha$-MSH), are derived. On release from axon terminals, $\alpha$-MSH binds to and activates neuronal melanocortin receptors, thereby decreasing food intake and favoring weight loss (28). POMC neurons are stimulated by leptin (29). Consistent with the down-regulation of STAT3 expression, a reduced expression of POMC was observed in the hypothalamus of IUGR rats. These findings indicate a blockade of leptin signaling as a consequence of exposure to uteroplacental insufficiency. Interestingly, neither the leptin secretion nor the hypothalamic leptin receptor expression was affected in IUGR animals. However, as fetal leptin is partly derived from the maternal circulation via transplacental passage in rodents (30), we cannot exclude a different transplacental transport between ligated and sham animals. The finding of unchanged expression of leptin receptor is apparently in contrast with a recent report showing increased leptin receptor expression in the hypothalamus of IUGR newborn rats (31). However, the different procedure used to obtain fetal growth restriction may account for the divergent results.

Our results suggest a leptin-independent mechanism leading to the reduced expression of STAT3 and POMC genes. STAT3 is expressed ubiquitously and is transiently activated by a large number of ligands, including epidermal growth factor, platelet derived growth factor, IL-6, ciliary neurotrophic factor, oncostatin $\mathrm{M}$, leukemia inhibitory factor, leptin, growth hormone, and prolactin, as well as by a number of oncogenic receptor and nonreceptor (Src-like) tyrosine kinases (17). Therefore, it is reasonable to speculate that factors different from leptin may be involved in the down-regulation of STAT3/POMC expression observed in IUGR newborn rats. However, as leptin expression was assessed in the whole hypothalamus, we cannot exclude a different expression in the individual nuclei.

In conclusion, the data presented here support the hypothesis that the exposure to an abnormal intrauterine environment alters the hypothalamic signaling pathways that regulate the energy homeostasis. Whether these changes are permanent and ultimately lead to metabolic alterations in adulthood remains to be established.

\section{REFERENCES}

1. Barker DJ, Winter PD, Osmond C, Margetts B, Simmonds SJ 1989 Weight in infancy and death from ischaemic heart disease. Lancet 2:577-580
2. Barker DJ, Osmond C, Golding J, Kuh D, Wadsworth ME 1989 Growth in utero, blood pressure in childhood and adult life, and mortality from cardiovascular disease. BMJ 298:564-567

3. Barker DJ, Hales CN, Fall CH, Osmond C, Phipps K, Clark PM 1993 Type 2 (non-insulin-dependent) diabetes mellitus, hypertension and hyperlipidemia (syndrome X): relation to reduced fetal growth. Diabetologia 36:62-67

4. Barker DJ 1995 Fetal origins of coronary heart disease. BMJ 311:171-174

5. Eriksson JG, Forsen T, Tuomilehto J, Osmond C, Barker DJ 2001 Early growth and coronary heart disease in later life: a longitudinal study. BMJ 322:949-953

6. Geremia C, Cianfarani S 2004 Insulin sensitivity in children born small for gestational age (SGA). Rev Diabet Stud 1:58-65

7. Fowden AL, Giussani DA, Forhead AJ 2005 Endocrine and metabolic programming during intrauterine development. Early Hum Dev 81:723-734

8. Unterman T, Lascon R, Gotway M, Oehler D, Gounis A, Simmons RA, Ogata ES 1990 Circulating levels of insulin-like growth factor binding protein-1 (IGFBP-1) and hepatic mRNA are increased in the small for gestational age fetal rat. Endocrinology 127:2035-2037

9. Simmons RA, Templeton LJ, Gertz SJ 2001 Intrauterine growth retardation leads to the development of type 2 diabetes in rat. Diabetes 50:2279-2286

10. Puglianiello A, Cianfarani S 2006 Central control of glucose homeostasis. Rev Diabet Stud 3:54-60

11. Obici S, Feng Z, Morgan K, Stein D, Karkanias G, Rossetti L 2002 Central administration of oleic acid inhibits glucose production and food intake. Diabetes 51:271-275

12. Obici S, Zhang BB, Karkanias G, Rossetti L 2002 Hypothalamic insulin signaling is required for inhibition of glucose production. Nat Med 8:1376-1382

13. Elmquist JK, Marcus JN 2003 Rethinking the central causes of diabetes. Nat Med 9:645-647

14. Prodi E, Obici S 2006 The brain as a molecular target for diabetic therapy. Endocrinology 147:2664-2669

15. Lim CP, Cao X 2006 Structure, function, and regulation of STAT proteins. Mol Biosyst 2:536-550

16. Gao Q, Wolfgang MJ, Neschen S, Morino K, Horvath TL, Shulman GI, Fu XY 2004 Disruption of neural signal transducer and activator of transcription 3 causes obesity, diabetes, infertility, and thermal dysregulation. Proc Natl Acad Sci USA 101:46614666

17. Cui Y, Huang L, Elefteriou F, Yang G, Shelton JM, Giles JE, Oz OK, Pourbahrami T, Lu CY, Richardson JA, Karsenty G, Li C 2004 Essential role of STAT3 in body weight and glucose homeostasis. Mol Cell Biol 24:258-269

18. Gorogawa S, Fujitani Y, Kaneto H, Hazama Y, Watada H, Miyamoto Y, Takeda K, Akira S, Magnuson MA, Yamasaki Y, Kajimoto Y, Hori M 2004 Insulin secretory defects and impaired islet architecture in pancreatic beta-cell-specific STAT3 knockout mice. Biochem Biophys Res Commun 319:1159-1170

19. Lee JY, Hennighausen L 2005 The transcription factor STAT3 is dispensable for pancreatic beta-cell development and function. Biochem Biophys Res Commun 334:764-768

20. Ghilardi N, Ziegler S, Wiestner A, Stoffel R, Heim MH, Skoda RC 1996 Defective STAT signaling by the leptin receptor in diabetic mice. Proc Natl Acad Sci USA 93:6231-6235

21. Darnell JE 1996 Reflections on STAT3, STAT5, and STAT6 as fat STATs. Proc Natl Acad Sci USA 93:6221-6224

22. Vaisse C, Halaas JL, Horvath CM, Darnell JE, Stoffel M, Friedman JM 1996 Leptin activation of Stat 3 in the hypothalamus of wild-type and ob/ob mice but not $\mathrm{db} / \mathrm{db}$ mice. Nat Genet 14:95-97

23. Myers MG, Cowley MA, Münzberg H 2008 Mechanisms of leptin action and leptin resistance. Annu Rev Physiol 70:537-556

24. Simmons RA, Gounis AS, Bangalore SA, Ogata ES 1992 Intrauterine growth retardation: fetal glucose transport is diminished in lung but spared in brain. Pediatr Res 31:59-63

25. Puglianiello A, Germani D, Antignani S, Scalia Tomba G, Cianfarani S 2007 Changes in the expression of hypothalamic lipid sensing genes in rat model of intrauterine growth retardation (IUGR). Pediatr Res 61:433-437

26. Morton GJ, Cummings DE, Baskin DG, Barsh GS, Schwartz MW 2006 Central nervous system control of food intake and body weight. Nature 443:289-295

27. Gluckman PD, Hanson MA 2004 Living with the past: evolution, development, and patterns of disease. Science 305:1733-1736

28. Fan W, Boston BA, Kesterson RA, Hruby VJ, Cone RD 1997 Role of melanocortinergic neurons in feeding and the agouti obesity syndrome. Nature 385:165-168

29. Cowley MA, Smart JL, Rubinstein M, Cerdán MG, Diano S, Horvath TL, Roger Cone RD, Low MJ 2001 Leptin activates anorexigenic POMC neurons through aneural network in the arcuate nucleus. Nature 411:480-484

30. Smith JT, Waddell BJ 2003 Leptin distribution and metabolism in the pregnant rat: transplacental leptin passage increases in late gestation nut is reduced by excess glucocorticoids. Endocrinology 144:3024-3030

31. Desai M, Gayle D, Han G, Ross MG 2007 Programmed hyperphagia due to reduced anorexigenic mechanisms in intrauterine growth-restricted offspring. Reprod Sci $14: 329-337$ 